\title{
Scanning electron microscopy of tinea nigra ${ }^{*}$
}

\author{
Isabelle Maffei Guarenti ${ }^{1}$ \\ Nara Moreira Rocha ${ }^{4}$
}

\author{
Hiram Larangeira de Almeida $\mathrm{Jr}^{2}$ \\ Ricardo Marques e Silva ${ }^{5}$
}

Aline Hatzenberger Leitão ${ }^{3}$

\begin{abstract}
Tinea nigra is a rare superficial mycosis caused by Hortaea werneckii. This infection presents as asymptomatic brown to black maculae mostly in palmo-plantar regions. We performed scanning electron microscopy of a superficial shaving of a tinea nigra lesion. The examination of the outer surface of the sample showed the epidermis with corneocytes and hyphae and elimination of fungal filaments. The inner surface of the sample showed important aggregation of hyphae among keratinocytes, which formed small fungal colonies. The ultrastructural findings correlated with those of dermoscopic examination - the small fungal aggregations may be the dark spicules seen on dermoscopy - and also allowed to document the mode of dissemination of tinea nigra, showing how hyphae are eliminated on the surface of the lesion.
\end{abstract}

Keywords: Bacterial infections and mycoses; Dermatomycoses; Fungi; Mycoses; Microscopy, electron, scanning

\section{INTRODUCTION}

Tinea nigra is a rare superficial mycosis. It is caused by a dematiaceous fungus that lives in hypersaline environments, due to its halophilic behavior, mostly in tropical and subtropical climates. This fungus is nowadays called Hortaea werneckii, but formerly was classified in genera Cladosporium, Crytococcus, Exophiala and Phaeonnellomyces. Some cases of tinea nigra have been reported as due to Stenella araguata, Scopulariopsis brevicaulis, Phoma eupyrena, and Chaetomium globosum..$^{1-7}$

This infection presents as asymptomatic brown to black maculae, single or multiple, with welldefined borders. It is more common in palmo-plantar regions, but lesions on other parts of the body have been reported. Typically it is unilateral and has centrifugal growth. It affects mostly female children and adolescents with fair skin and is thought to be acquired through superficially abraded skin., ${ }^{1,2,3,-10}$

Diagnosis is clinical and must be confirmed with direct mycological examination of the lesion, after clarification with potassium hydroxide, or with culture in Sabouraud dextrose agar medium at room temperature. Irregular septate dematiaceous hyphae are observed in the first exam, while slow-growing, moist and shiny black colonies are seen in the second. The brown color of dematiaceous fungi occurs because of the presence of melanin in the cell wall. ${ }^{1-4,8-11}$

Making the correct diagnosis is important because lesions can be misdiagnosed as malignant melanoma or junctional melanocytic nevus and unnecessary biopsies may be performed. Therefore, dermoscopy has been used as a clinical adjunctive tool in differentiating tinea nigra from melanocytic lesions. Dermoscopic findings of tinea nigra are homogeneous brown nonmelanocytic pigmented reticular-like pattern with spicules that do not follow the dermatoglyphic lines. ${ }^{1,12-15}$

Treatment of tinea nigra can be performed with topical antifungal and keratolytic agents, with complete resolution in two to four weeks. The use of terbinafine and butenafine has been reported recently. In the literature, there are also case reports of spontaneous cure of this mycosis. . $^{-4,9,16-18}$

\section{CASE REPORT}

We examined an 11-year-old girl who presented with a 2-month history of an asymptomatic hyperpigmented lesion on her right palm. She had no relevant history of local trauma neither comorbidities. Physical examination revealed a brown irregularly

\footnotetext{
Received on 15.05.2013.

Approved by the Advisory Board and accepted for publication on 20.07.2013.

Work performed at the Universidade Federal de Pelotas (UFPEL), Universidade Católica de Pelotas (UCPel) - Pelotas (RS), Brazil.

Conflict of interest: None

Financial funding: None

Catholic University of Pelotas - Pelotas (RS), Brazil.

Federal University and Catholic University of Pelotas - Pelotas (RS), Brazil.

Catholic University of Porto Alegre - Porto Alegre (RS), Brazil.

EMBRAPA CPA-CT - Pelotas (RS), Brazil.

Federal University of Pelotas - Pelotas (RS), Brazil. 
shaped macula with well-delimited borders (Figure 1A). Dermoscopy examination demonstrated a homogeneous nonmelanocytic pigmented pattern with spicules in the irregular macula (Figure 1B).

As electron microscopy findings of tinea nigra are limited, this study was aimed at further elucidation of the fine structure of this dermatosis.

Specimens were collected by superficial shaving of a tinea nigra lesion, cut horizontally with scalpel without bleeding, removing a fragment of epidermis for scanning electron microscopy and for culture on Sabouraud agar medium. The sample and a fragment of the culture were routinely prepared for scanning electron microscopy, the culture was also examined for correct identification of the causative agent.

The culture in Sabouraud agar medium at room temperature produced, after 10 days, moist black colonies (Figure 1C). Scanning electron microscopy (SEM) examination of the fungal culture showed multiple hyphae with conidiogenous loci producing conidia laterally and terminally on hyphae, or from the lateral walls of hyphae - sympodial conidiogenesis (Figure 1D). A few conidiogenous cells with annellations were also found in the culture, typical findings for Hortaea werneckii.

On the outer surface of the sample scanning electron microscopy showed the epidermis with corneocytes and hyphae and elimination of fungal filaments (Figure 2). The inner surface of the sample was also examined, since some fragments were placed inverted for the examination on the stub. In these specimens, important aggregation of hyphae among keratinocytes was seen, which formed small fungal colonies (Figure 3).
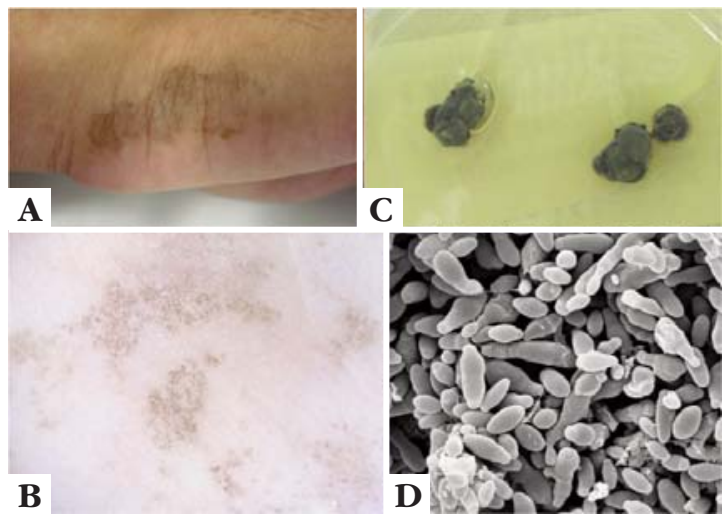

FigURE 1: A. brown macula on the right palm; B. dermoscopic exam of the lesion with homogeneous nonmelanocytic pigmented pattern with spicules; C. culture on Sabouraud's agar medium showing moist black colonies of Hortaea werneckii; D. SEM examination of the culture showing multiple hyphae with bottle-shaped and globose conidiogenous cells $(2400 \mathrm{x})$
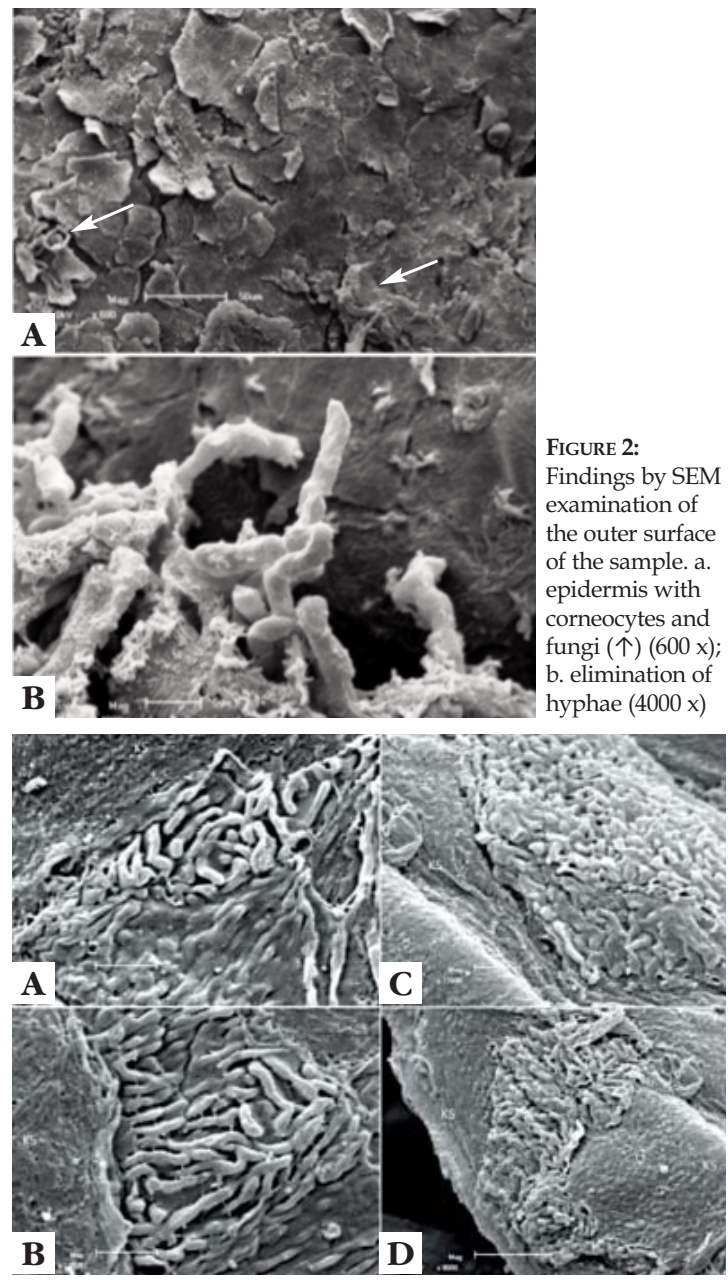

FIGURE 3: SEM examination of the inner surface of the sample showing aggregation of hyphae among keratinocytes, forming small fungal colonies. KS = keratinocyte inner surface. $(8000-16000$ x)

\section{DISCUSSION}

Tinea nigra is a rare superficial mycosis, whose causative agent is nowadays called Hortaea werneckii, after different opinions on its taxonomy presented by many mycologists. According to Nishimura e Miyaji this fungus has a combination of sympodial and annellidic conidiogenesis, differentiating it from the Exophiala species, which has been shown in a few studies, including this presented here. ${ }^{19-23}$

Furthermore, these SEM findings correlate with those of dermoscopic examination, since the found hyphae aggregations among keratinocytes should be the observed brown spicules on dermoscopy. SEM also allowed to document the mode of dissemination of tinea nigra, showing how hyphae are eliminated on the surface of the lesion. 


\section{REFERENCES}

1. Xavier MH, Ribeiro LH, Duarte H, Saraça G, Souza AC. Dermatoscopy in the diagnosis of tinea nigra. Dermatol Online J. 2008;14:15.

2. Tilak R, Singh $S$, Prakash $P$, Singh DP, Gulati AK. A case report of tinea nigra from North India. Indian J Dermatol Venereol Leprol. 2009;75:538-9.

3. Bonifaz A, Badali H, de Hoog GS, Cruz M, Araiza J, Cruz MA, et al. Tinea nigra by Hortaea werneckii, a report of 22 cases from Mexico. Stud Mycol. 2008;61:77-82.

4. Rossetto AL, Cruz RC. Tinea nigra in geographical forms of "heart" and "parrot beak". An Bras Dermatol. 2011;86:389-90.

5. Kogej T, Stein M, Volkmann M, Gorbushina AA, Galinski EA, Gunde-Cimerman N. Osmotic adaptation of the halophilic fungus Hortaea werneckii: role of osmolytes and melanization. Microbiology. 2007;153:4261-73.

6. McGinnis MR, Sigler L, Rinaldi MG. Some Medically Important Fungi and Their Common Synonyms and Names of Uncertain Application. Clin Infect Dis. 1999;29:728-30.

7. Revankar SG, Sutton DA. Melanized Fungi in Human Disease. Clin Microbiol Rev. 2010;23:884-928

8. Giraldi S, Marinoni LP, Bertogna J, Abbage KT, de Oliveira VC. Tinea nigra: six cases in Parana state. An Bras Dermatol. 2003;78:593-600.

9. de Almeida Jr HL, Dallazem RN, Santos LS, Hallal SAS. Bilateral tinea nigra in a temperate climate. Dermatol Online J. 2007;13:25

10. Revankar SG. Dematiaceous fungi. Mycoses. 2007;50:91-101.

11. Dixon DM, Polak-Wyss A. The medically important dematiaceous fungi and their identification. Mycoses. 1991:34:1-18

12. Haneke E, Kienlein-Kletschka B. Histology and electron microscopy of tinea nigra. Mykosen. 1983;26:514-20.

13. Piliouras P, Allison S, Rosendahl C, Buettner PG, Weedon D. Dermoscopy improves diagnosis of tinea nigra: a study of 50 cases. Australas J Dermatol. 2011;52:191-4.

14. Rezusta A, Gilaberte Y, Betran A, Gene J, Querol I, Arias M, et al. Tinea nigra: a rare imported infection. J Eur Acad Dermatol Venereol. 2010;24:89-91.

15. Paschoal FM, de Barros JA, de Barros DP, de Barros JC, Filho CD. Study of the Dermatoscopic Pattern of Tinea Nigra: Report of 6 Cases. Skinmed. 2010;8:319-21.

16. Rossetto AL, Cruz RC. Spontaneous cure in a case of Tinea nigra. An Bras Dermatol. 2012;87:160-2.

17. de Almeida HL Jr. Successful treatment of Tinea nigra palmaris with topical terbinafine. An Bras Dermatol. 2000;75:639-40.

18. Rossetto AL, Cruz RCB. Tinea nigra: successful treatment with topical butenafine. An Bras Dermatol. 2012;87:939-41.

19. Varga VES, Godoy P. Tinea nigra. In: Sidrim JJC, Rocha MFG. Micologia médica à luz de autores contemporâneos. Rio de Janeiro: Guanabara Koogan; 2004. p.12:124-128
20. Zaitz C, Campbell I, Marques SA, Ruiz LRB, Framil VMS. Morfologia, reprodução e taxonomia dos fungos. In: Zaitz C, Campbell I, Marques SA, Ruiz LRB, Framil VMS. Compêndio de micologia médica. Rio de Janeiro: Guanabara Koogan; 2010. p.8:89-98.

21. Diniz LM. Study of nine observed cases of Tinea Nigra in Greater Vitória (Espirito Santo state, Brazil) over a period of five years. An Bras Dermatol. 2004;79:305-10.

22. Nishimura K, Miyaji M. Further studies on the phylogenesis of the genus Exophiala and Hortaea. Mycopathologia. 1985;92:101-9.

23. Uezato H, Gushi M, Hagiwara K, Kayo S, Hosokawa A, Nonaka S. A case of tinea nigra palmaris in Okinawa, Japan. J Dermatol. 2006;33:23-9.

\author{
MAILING ADDRESS: \\ Hiram Larangeira de Almeida Jr \\ Duque de Caxias, 250 \\ 96030-000 -Pelotas - RS \\ Brazil \\ E-mail: hiramalmeidajr@hotmail.com
}

How to cite this article: Guarenti IM, Almeida Jr HL, Leitão AH, Moreira Rocha N, Marques e Silva R. Scanning electron microscopy of Tinea nigra. An Bras Dermatol. 2014;89(2):334-6. 